\title{
The Effect of Wood Knot as a Defect on Modulus of Elasticity (MOE) and Damping Correlation
}

\author{
Mohammad Ali HOSSEIN*, Mahdi SHAHVERDI, Mehran ROOHNIA \\ Karaj Branch, Islamic Azad University, Department of Wood and Paper Science and Technology, \\ Karaj,Iran;ma.hossein64@gmail.com (*correspondingauthor)
}

\begin{abstract}
This research was carried out to investigate the influence of knots on modulus of elasticity and on damping factor of vibration. Rectangular bars from Cupressus arizonica wood were used. Five individual trees were selected, and samples of $2^{*} 2^{*} 36 \mathrm{~cm}$ were cut and conditioned at $21^{\circ} \mathrm{C}$ and $65 \%$ relative humidity. Experiments based on free vibration and free-free bar method were performed and controlled in static bending test due to their modulus of elasticity. As expected, this kind of defect showed significant effects on modulus of elasticity, damping factor of vibration and FFT diagrams. A significant relation was observed between modulus of elasticity and damping factor between the two dynamic and static methods, but this relation decrease about 60\% in knot-containing specimens. Modes of FFT spectrums of defect-free specimens were pick-like, symmetric specimens without any breaks, but the spectra of knotcontaining samples spectrums were entirely asymmetric. Applying these diagrams in order to recognize the suitability or unsuitability of a piece of wood for specific applications, especially due to internal defects that are not visible, could be very important, and must be considered in future research.
\end{abstract}

Keywords: Cupressus, damping, FFT, knots, Modulus of Elasticity, vibration

\section{Introduction}

Defects have negative effects on wood construction's lifetime, so to find their footprints-even small ones-can ensure investors to think of such kind of constructions (Cam, 2005). In this regard, non-destructive testing, such as Stress Wave and Transverse Vibration Techniques, can be accurate equipments to evaluate the wood products quality. Whereas scientists have reported significant relation between non-destructive tests and static bending results (Halabe, 1995), these methods have improved and advanced during the last years (Bodig and Jane, 1989).

These tests can be used to evaluate wood and wood products' properties without any destruction of the samples. Wood structure, dimension, physical and mechanical properties, dynamic response, and even its defects, such as knots or internal stresses, can be identified utilizing NDT (Ross, 1994).

One of the most effective NDT methods is the vibration method, which is used in this research (Sedik et al., 2010).

Alavitabar et al. (2009) investigated the quality and damping factor of Iranian Beech timbers by free vibration method and significant effects were observed between modulus of elasticity and damping factor.

Investigating the effect of free vibration and static methods on modulus of elasticity and damping factor of Cupressus arizonica showed significant correlation between these methods (Roohnia and Tajdini, 2008).
Roohnia et al. (2006) evaluated the specific modulus of elasticity and shear modulus (radial and tangential) across the Cupressus arizonica logs. In this research Free Vibration based on Free-Free Bar was used and claimed that specific MOE decreases significantly from pith to bark.

Roohnia and Yavari (2009) mentioned that the existence of crack in wooden beam in free vibration method affects the correlation between radial and tangential shear modulus and decreases this correlation significantly.

Wood defects can be categorized as either natural (growth defects) or defects created during wood processing. The former defects are visible, but internal defects (mostly knot) are invisible. The latter ones are able to influence many physical and mechanical properties of wood, making it unsuitable for some applications and rendering it undesirable even if no defect is apparent from the outside view.

In non-destructive tests, defects can have special footprints or signs. In the present research such signs are recognized based on both mechanical properties and the FFT Spectra obtained from free vibrations, using a free-free bar format.

The static bending method was also used in comparison with the dynamic method. It should be noted that static methods are time-consuming compared with dynamic methods.

Free vibration based on a free-free bar method (Brancheriau and Bailleres, 2002) was used to evaluate modulus of elasticity (MOE), shear modulus $\left(G_{L R}\right.$ and 
146

$\mathrm{G}_{\mathrm{LT}}$ ), and damping factor (NDT tand) of specimens. FFT spectra were used to compare knot-containing and defectfree bars.

\section{Materials and methods}

\section{Specimen preparation}

Cupressus arizonica specimens were used. Five individual trees were selected from plantations in Karaj, Iran (Faculty of Agriculture and Natural Resources, Tehran University) which were equal in diameter and age. Logs were cut at a distance of $150 \mathrm{~cm}$ from breast height. From each log one disk $(10 \mathrm{~cm}$ thick) was prepared for tests, such as discoloration, eccentric defect and fibers inspection, to ensure the absence of reaction wood.

The remaining portion was divided into four specimens (fragments), located near the pith (NP), between pith and middle (MD1), between middle and bark (MD2) and near bark (NB) (Fig. 1). Specimens with nominal dimensions of $2^{*} 2^{*} 36 \mathrm{~cm}\left(\mathrm{R}^{*} \mathrm{~T}^{*} \mathrm{~L}\right)$ were cut from each fragment. After separating knot-containing and knot-free specimens, they were kept in a conditioning chamber, set at $21^{\circ} \mathrm{C}$ and $65 \%$ relative humidity for two weeks, until the moisture content reached $12 \%$.

\section{Free vibration based on free-free bar measurements}

Free vibrations were detected by free-free bar measurements (NDT-Lab software (Roohnia et al., 2007)), with each beam resting on soft thin rubber. Individual impacts were applied on both radial and tangential surfaces, exciting the beam to vibrate in tangential (LT) and radial (LR) directions, respectively (Fig. 2). The first three modes of vibration were obtained from the resulting FFT spectra (Fig. 3). Then the specific longitudinal modulus of elasticity and shear modulus were evaluated using Timoshenko beam equations (as previously described in Bordonne,
1989; Brancheriau and Bailleres, 2002; Roohnia et al., 2010). After obtaining the $\mathrm{n}^{\text {th }}$ frequency mode through Fourier Transform, considering $\mathrm{a}^{\mathrm{n}}$ and $\mathrm{b}^{\mathrm{n}}$, the value of longitudinal specific modulus of elasticity was determined using a linear regression formula as following:

$$
\begin{aligned}
& a_{n}=\left(\frac{E}{\rho}\right)-\left(\frac{E}{K \times G_{i j}}\right) b_{n} \\
& b_{n}=\frac{4 \pi^{2} l^{2} f_{n}^{2} F_{2 n}}{X_{n}} \\
& a_{n}=\frac{\left[4 \pi^{2} l^{2} f_{n}^{2}\left(I+\alpha F_{l n}\right)\right]}{\alpha X_{n}} \\
& X_{n}=m_{n}^{4} \\
& \alpha=\frac{I}{A l^{2}}
\end{aligned}
$$

where I: moment of inertia; A: cross section area; 1: length of the specimen; $\mathrm{K}$ : shape coefficient (the value of $5 / 6$ can be used for a rectangular cross section); $G_{i j}$ : shear modulus in plane of vibration $\left(G_{L T}\right.$ or $\left.G_{L R}\right)$; $p$ : specific gravity; $f_{n}$ : frequency of the $\mathrm{n}^{\text {th }}$ mode of vibration obtained from FFT spectrum; $m_{n}$ : the $n^{\text {th }}$ results in following Equation:

$$
m_{n}=\frac{(2 n+1) \pi}{2}
$$

In Equations 2 and 3, $F_{1 n}$ and $F_{2 n}$ can be calculated as following:

$$
\begin{aligned}
& F_{1 n}=\Theta^{2}\left(m_{n}\right)+6 \Theta\left(m_{n}\right) \\
& F_{2 n}=\Theta^{2}\left(m_{n}\right)-2 \Theta\left(m_{n}\right) \\
& \Theta_{\left(m_{n}\right)}=\frac{\left[m_{n} \tan \left(m_{n}\right) \tanh \left(m_{n}\right)\right]}{\left[\tan \left(m_{n}\right)-\tanh \left(m_{n}\right)\right]}
\end{aligned}
$$

\section{Static bending}

After testing the specimens by the dynamic method, static bendig tests were also carried out on both knotcontaining and knot-free specimens. This method is in accordance to ISO-3133, and the results were compared to

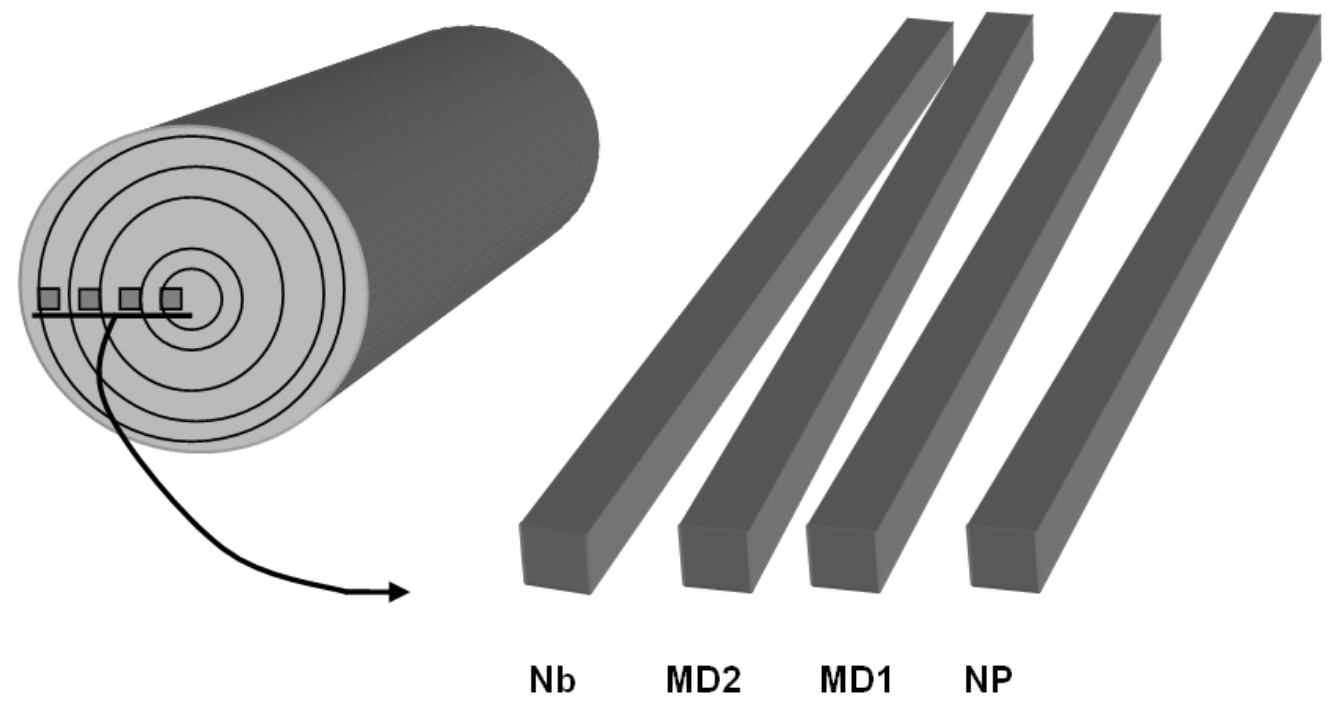

Fig. 1. Four locations from pith to bark [specimens dimensions: $\left.2^{*} 2^{*} 36 \mathrm{~cm}\left(\mathrm{R}^{*} \mathrm{~T}^{*} \mathrm{~L}\right)\right]$ 


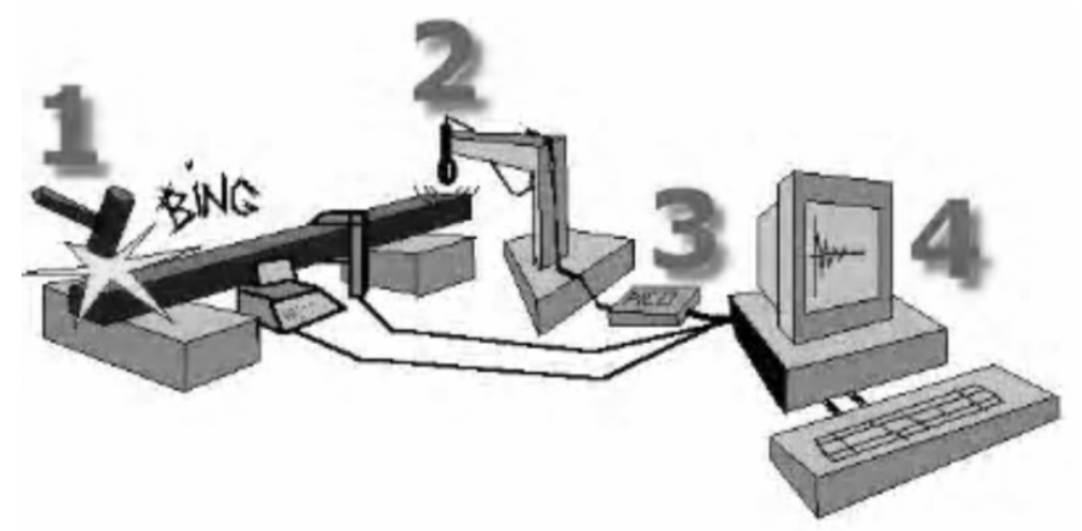

Fig. 2. Schematic view of the most common setup for free vibration on a free-free bar test

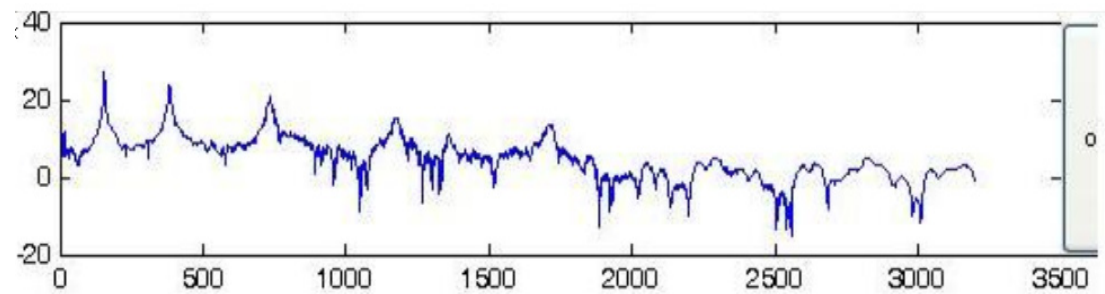

Fig. 3. Fast Fourier Transform (FFT) spectrum showing the first three modes of vibration. $\mathrm{Y}$ axis is corresponding to the amplitude in $\mathrm{Db}$, and $\mathrm{X}$ axis to the frequency in $\mathrm{Hz}$

those from the dynamic method. Appling the univariate analysis of variances, the effects of defects on elastic parameters were evaluated.

\section{Results and discussion}
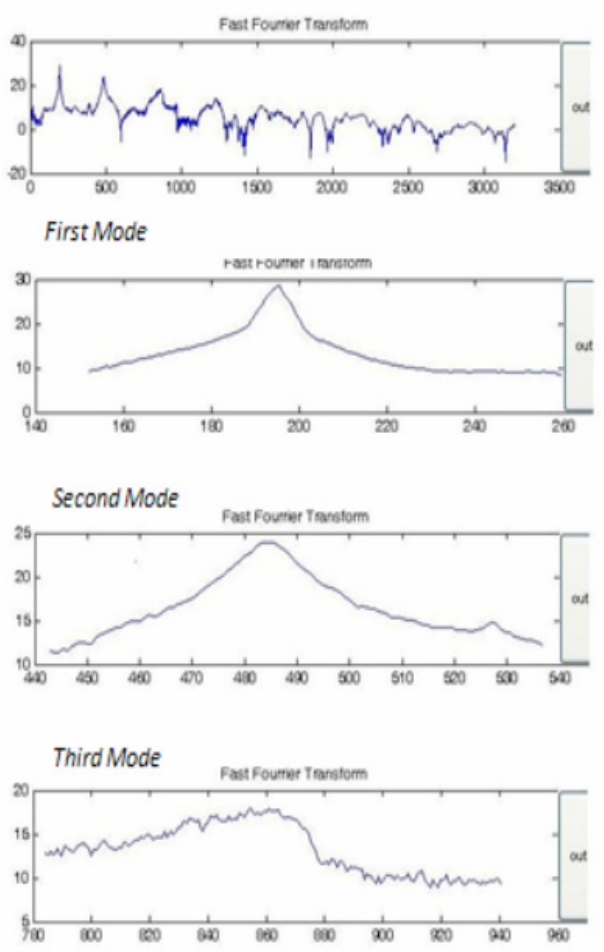

In order to eliminate the effect of individual trees upon results, each tree was considered as an experimental block for statistical analysis. The results indicated that there was no significant difference between the five replicated trees.


Fig. 4. Fast Fourier Transform spectra for knot-free (Left) and knot-containing (Right) beams. Modes of vibrations in FFT spectrums of knot-free specimens were pick-like, symmetric, and without any breaks, but knot-containing samples yielded entirely asymmetric spectra 



Fig. 5. Modulus of elasticity in static and dynamic method for Fig. 6. Static modulus of elasticity and damping in knot-containknot-containing and knot-free specimens from pith to bark

ing and knot-free specimens from pith to bark

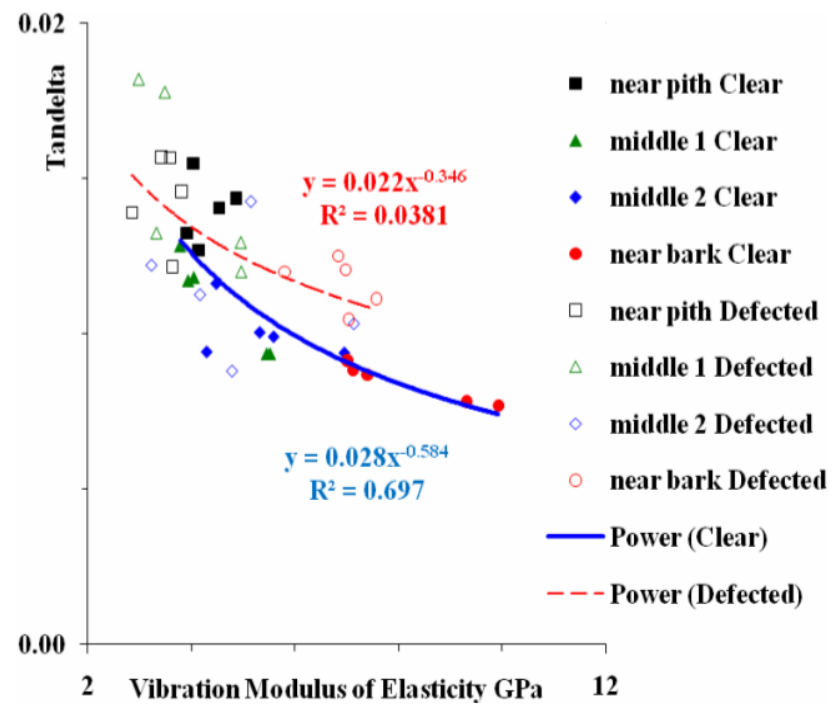

Fig. 7. Dynamic modulus of elasticity and damping in knot-containing and knot-free specimens from pith to bark

Modes of FFT spectrums of knot-free specimens were pick-like and symmetric, without any breaks, but the spectra of knot-containing samples spectrums were entirely asymmetric (Fig. 4).

Significant correlations between vibration test results (dynamic method) and the static bending method in term of modulus of elasticity both in knot-containing $\left(\mathrm{R}^{2}=0.94\right)$ and knot-free specimens $\left(\mathrm{R}^{2}=0.51\right)$ were observed, as mentioned by Halabe et al. (1995). However, the correlation coefficient was smaller in knot-containing specimens. Vibration tests yielded higher values for MOE (about 12\% in clear and 19\% in defected specimens), and as it could be predicted, the effect of a knot on modulus of elasticity was significant for both methods (static and dynamic), but the interactions between defects and the location of specimen were not significant (Fig. 5). The correlations between radial and tangential shear modulus were not significant in knot-containing specimens, being in accordance with Roohnia et al. (2010).

As shown in Figs. 6 and 7, there is a strong correlation between MOE and damping factor in both dynamic and static method in knot-free beams, but this correlation was subject to change (reduced by nearly 60\%) in knot-containing specimens. Alavitabar et al. (2009) also concluded to same results for Iranian beech wood. Roohnia et al. (2006) reported that specific MOE significantly decreased from pith to bark, fact that can be seen as a result of this research too (Fig. 5).

\section{Conclusions}

Based on a data survey presented as a Pearson correlation table, a correlation could be recognized between damping factor $(\tan \delta)$ and modulus of elasticity (MOE) 
in static and dynamic methods. In knot-free specimens there were significant correlations between static and $\mathrm{dy}$ namic MOE with damping factor; these factors showed in knot-containing specimens that the correlation between the damping factor and MOE of static method was reduced by nearly $60 \%$. The same correlation between damping factor and MOE of dynamic method was established, but a 22\% reduction was observed. Significant correlation was observed between the MOE of static and dynamic methods, even though in knot-containing samples it has considerably decreased. Damping factor increased in both static and dynamic method for knot-containing specimens, which emphasizes the negative effect of knot on wood mechanical properties. Concerning the variation of these parameters at various locations, the $\mathrm{MOE}$ value increased in an obvious way from pith to bark; on the contrary, the damping factor decreased form pith to bark. It can be predicted that specimens of this species from outer parts of the trunk, with smaller damping and greater MOE, would be better suited to applications involving elastic properties. Vibration-based methods can provide a way to evaluate the modulus of elasticity, especially in cases that yield have relatively high values; this dynamic method is also suitable for evaluation of the MOE both in clear and knot-containing specimens. The operator must interpret the dynamic MOE values considering that they are about 12 to $20 \%$ larger than the true values.

\section{References}

Alavitabar SE, Roohnia M, Tajdini A (2009). Investigation on Quality and Damping in Iranian Beech Timbers. J Sci Techn Natural Resour 4(2):59-68.

Bodig J, Jane B (1989). Mechanics of Wood and Wood Composites (Persian translation), Tehran University Press.

Bordonné PA (1989). Module dynamique et frottement intérieur dans le bois: Mesuressur poutres flottantes en vibrations naturelles. Thèse de doctorat de l'INP de Lorrainesoutenue à Nancy, p. 154 .
Brancheriau L, Bailleres H (2002). Natural vibration analysis of clear wooden beams: A theorical review. Wood Sci Technol 36:347-365.

Cam E, Orhan S, Luy M (2005). An analysis of cracked beam structure using impact echo method. NDT and E Internat 38:368-373.

Halabe UB, Gangadhar MB, Hota VSG, Ross RJ (1995). Nondestructive Evaluation of Green Wood Using Stress Wave and Transverse Vibration Techniques. Mater Eval 55(9):1013-1018.

Roohnia M, Doosthosseini K, Kademieslam H, Gril J, Bremaud I (2006). Study on variations of specific modulus of elasticity and shear modulus in Arizona Cypress wood, using vibration method. Iran J Natural Resour 59(4).

Roohnia M, Bremaund I, Guibal D, Tajdini A (2007). NDTLAB: Software to evaluate the mechanical properties of wood. International Conference on Integrated Approach to Wood Structure, Behaviour and Applications. Joint meeting of ESWM and Cost Action E35. Florence, Italy.

Roohnia M, Tajdini A (2008). Study on the Possibility of Mechanical Measurements on Wood Using Free Vibration Method and Compare with the Static and Forced Vibration Methods. J Agricult Sci 13(4):1017-1027.

Roohnia M, Yavari A (2009). Rectangular beams of poplar wood in free vibration with different end cracked sizes. The International Conference on Advanced Materials for Application in Acoustics and Vibration (AMAAV). Center for Advanced Materials, The British University in Egypt. Cairo-Egypt.

Roohnia M, Yavari A, Tajdini A (2010). Elastic parameters of poplar wood with end-cracks. Ann Forest Sci 67:409.

Ross RJ (1994). Review of Nondestructive Evaluation of Timber. Proceedings of conference; September 12-14; Charlestown, MA. Washington, DC: Naval Historical Center, p.78-91.

Sedik Y, Hamdan S, Jusoh I, Hasan M (2010). Acoustic Properties of Selected Tropical Wood Species. J Nondestruct Eval 29:38-42. 